\title{
SELECTING A SMALL PORTFOLIO OF EQUITIES: ONE-STOP SHOPPING APPROACH TO SCREENING
}

\author{
MARTIN BOĎA, MÁRIA KANDEROVÁ \\ Matej Bel University in Banská Bystrica, Faculty of Economics, \\ Department of Quantitative Methods and Information Systems, \\ Tajovského 10, 97590 Banská Bystrica, Slovakia \\ email:martin.boda@umb.sk, maria.kanderova@umb.sk
}

\begin{abstract}
Investing into equities requires that a pre-selection of candidate equities be made, which is frequently accomplished by means of a screening criterion such as market capitalization, a fundamental indicator of past performance. The paper considers four screening criteria market capitalization, two multiples (the $P / B$ and $P / E$ ratios) and historical yield - and investigates how the pre-selection choice based on any of these criteria and orientation towards small/low or big/high poles of equity styles affects the performance of a small portfolio comprising 50 equities at most. The goal of the investigation undertaken in the paper is to assess usefulness of these distant poles of equity styles and evaluate their performance against trending patterns of the market. The method is experimental and in order to assure robustness of results it employs 5 consecutive four-year datasets from 2009 to 2016 and three conceptually different methods of portfolio selection, setting the S\&P 500 Index as benchmark. The results indicate that superiority of equity styles and selection methods is contingent on market cycle: in bull markets with steady growth, equity styles with small/low polarity seem more dependable, but when market price patterns change between bull and bear markets, big/high poles seem guarantee better performance.
\end{abstract}

Key words: equity style, asset pre-selection, market capitalization, multiple, historical yield, performance.

JEL codes: $G 11$

\section{DOI: 10.15611/amse.2017.20.04}

\section{Introduction}

An earlier study of ours investigated different equity style preferences and their effect upon the performance of a small share portfolio (see Bod'a and Kanderová, 2017). Albeit the setting of that study was somewhat limited to portfolio optimization based on linear and quadratic tracking, it assisted in establishing favourability of linear tracking over quadratic tracking and it also indicated that equity styles do not display universal validity over time but their preferability changes in correspondence with the life cycle of the market. In times of bullish markets, growth or small-capitalization equity styles seem preferable, but when markets turn bearish, value and possibly large-capitalization equity styles are inclined to outperform their growth and small-capitalization pendants. This finding merits further inquiry, which is undertaken in this present paper. The goal of the paper is to assess usefulness of distant poles of equity styles and evaluate their performance against trending patterns of the market. Whereas it is obvious that "trending market patterns" means the general tendency of a market to swing up or decline, the term "distant poles" of an equity style is intended to mean opposing approaches that any equity style embodies. Equity styles are recognized as 
preferences for some market segments and are defined by means of a suitable quantifiable indicator such as market capitalization or a multiple. Small or large levels of market capitalization and low or high values of a multiple give rise to distinct market segments and underlie different and distant equity styles. Investing on the basis of one particular screening criterion is known as one-stop shopping (see e.g. Penman, 2010, p. 80), which explains the title of the paper and highlights that only one screening criterion is considered in the paper at a time.

In order to preserve consistency and maintain comparability with our previous study (Bod'a and Kanderová, 2017), we keep most of the general set-up unaltered. In consequence, the present empirical experiment also focuses upon a small investor who is considering creating a portfolio of at most 50 equities represented in the Standard \& Poor's 500 (S\&P 500) Index. Having accepted the said index as a natural benchmark for investment, the investor must make in this regard two crucial choices: In the first stage, he must make a suitable pre-selection of shares for later portfolio selection; and in the second stage, their effective composition must be determined using a suitable portfolio selection procedure. Although the first stage may be implemented quite heuristically, a more professional and recommendable implementation is using a particular equity style based on an appropriate screening criterion. In this paper, we make use of a total of four classification criteria for screens, out of which one reflects size, two represent the anticipations that the market feels about value and future growth prospects of individual shares, and one is past performance. Market capitalization defines segments of small-cap and big-cap shares, whereas two multiples - the price-to-book ratio and the priceto-earnings ratio - differentiate segments of value shares (for low values of these multiples) and growth shares (for high values attained by these multiples). The last criterion is historical yield. There are good explanations and theoretical background for small-capitalization and large-capitalization investing as well as for value and growth investing; but whatever they are, the result is that opposite segments of an active market are favoured and contrasted. In this unidimensional approach, only one screening criterion is used with any equity style; and thus investing here goes à la one-stop shopping. Shares identified through distant poles of equity styles pass into the second stage for which in the paper three distant methods of weight determination are allowed for: linear tracking, expected exponential utility maximization and market capitalization allocation. All these three portfolio selection methods are consistent with the investor's construal of the S\&P 500 Index as benchmark. Whereas linear tracking does the job of imitating the historical performance of a given benchmark, market capitalization allocation partially replicates a market index and is compatible with the chosen benchmark. Eventually, the approach of maximizing expected exponential utility is implemented here by deriving the input parameters from the performance of the benchmark index.

The paper presents an empirical investigation using five consecutive overlapping four-year datasets of a weekly frequency between 2009 and 2016, in which a small investor employs a two-year history for estimation and portfolio selection and his investment horizon is another two years. As outlined, four diverse portfolio selection methods are entertained and put to the test sequentially with 10, 20, 30, 40 and 50 shares represented in the S\&P 500 fulfilling the function of a benchmark. Out-of-sample performance exhibited through the investment horizon is the main guide to assessing which equity style, portfolio selection algorithm and nominal portfolio size is favourable.

The remainder of the paper is made up of four more sections. Section 2 gives some rationale on investing based on screening, contrasts and briefly explains the three methods of portfolio selection and the model of transaction costs applied in the paper. Section 3 
comments on the methodology of the paper and describes the adopted experimental design. Section 4 present the results attained, which are discussed in Section 5 that concludes.

\section{General Notes on Screening and Portfolio Selection}

Regardless of the actual conditions of an investment situation, two matters should be seen to: some assets must always be pre-selected out of the universe of assets eligible for investing, and their weights must be specified. If the buy-and-hold strategy is not pursued, then also some method of portfolio revision and rebalancing must be taken into account. However, initially, asset-preselection is guided by the conviction of the investor that some assets are better than others and should be invested into, and that this superiority will not perish or diminish over time. One possibility of branding such assets in the case of equity investing is relating them to factors that are traditionally related to abnormal returns, i.e. returns earning the required rate of return (see Lofthouse, 1994, p. 51). Good examples are high or low multiples (such as the $\mathrm{P} / \mathrm{B}, \mathrm{P} / \mathrm{E}$ or $\mathrm{P} / \mathrm{S}$ ratio), big or small size, and historical yield. There are economic reasons (that follows from the very construction of multiples) why one would wish to invest into equities with high or low values of multiple, there are natural explanations why one would prefer investing into large companies (that set out trends for the market) or small companies (that are mostly credited with good growth prospects). As a matter of fact, it is very unusual to invest into equities whose historical record was unsatisfactory and their past returns were negative. Be that as it may, with each screening criterion two poles can recognized which stems from the fact that any measurable (and reasonable) criterion affords ranking of equities from those with smallest (lowest) and largest (highest) values. Using market capitalization as a criterion of size, equities are classified into small caps and big caps, using the $\mathrm{P} / \mathrm{B}$ or $\mathrm{P} / \mathrm{E}$ ratio, equities are classified into contrarian (value) shares (with low ratios) and into glamour (growth) shares (with high ratios). In the case of historical performance, shares with a history of small (possibly negative) yields are just a theoretical complement to shares with past high yields (that are otherwise desirable). When multiples are employed for screening, a problem frequently emerges that some equities have a negative value on a multiple, in such a case these equities are simply discarded and disqualified. Although it is possible to put several screening criteria to use at a time, this paper considers only one-stop shopping (i.e. that only a single criterion is made use of).

Having a pre-selection of candidate shares, the resultant portfolio is selected and its weights are determined by means of three competitive approaches that are quite representative of best practices upheld in the theory and practice of investment. Two approaches are formal and are mathematically or statistically based (linear tracking and maximum utility maximization) whereas one approach obeys the very internal structure of the market (market capitalization). In tracking generally, the investor selects a portfolio of shares in such a way that the discrepancy between the resultant portfolio returns and the benchmark returns is minimal. Especially, in linear tracking, this discrepancy is embodied by maximum absolute deviation. Another popular possibility is to select portfolios in Markowitzian mean-variance space balancing the expected portfolio return and its risk measured by volatility, which is implemented here through maximizing expected exponential utility when returns are elliptically distributed. To some degree, assuming the investor with an exponential utility function is simplification, but it results in an optimization task that depicts brilliantly the need to find a trade-off between (mean) return and investment and is a Taylor-expansion approximation also to non-exponential utilities (see e.g. Markowitz, 1987, p. 60; Alexander, 2008, pp. 230, 234). Interestingly, both these approaches are linked or can be linked directly with the idea of imitating a benchmark investment. The reason being, tracking does this utterly whereas expected utility maximization only requires that a risk aversion coefficient be 
determined, which can safely be rendered by studying the performance of the benchmark (see Grinold and Kahn, 1995, pp. 77-78). The last option to fund allocation entertained here specifies weights from the market capitalization of individual assets. The capitalization method is but a natural extension of screening on market capitalization, multiples and past performance - shares are ranked under a suitable such criterion and their weights are decided by their market capitalization (see e.g. Grinold and Kahn, 1995, pp. 276-277). The three methods employed in the paper are clarified in brief.

For the sake of presentation, it is assumed that $T$ historical observations of (preferably logarithmic) returns are available and that $K$ assets are pre-selected with the use of a screening criterion. Let $Y_{t}, x_{1, t}, \ldots, x_{K, t}$ denote the benchmark return and $K$ share returns at time $t$, respectively, wherein $t \in\{1, \ldots, T\}$. The historical mean return of a $k$-th share is denoted here as $m_{k}$ and an $k \times l$ element of an appropriate positive definite estimate of the covariance matrix is denoted as $s_{k l}$. It is assumed that a $k$-th share has a total capitalization of $\Pi_{k}$ in the market at the time of portfolio selection and that the investor's risk aversion coefficient is $\psi$ (where $\psi>0$ ). It is possible to specify $\psi$ with some good knowledge of his risk preferences and attitudes, but a more practicable approach consistent with the importance of benchmark to the investor is described and justified in Grinold and Kahn (1995, pp. 77-78) who find that the benchmark portfolio is mixed with a risk-free asset, then the maximum utility is achieved only in the case of investing the full budget to the benchmark at a specific value of the coefficient of risk aversion. So long as this coefficient is obtained by the historical method, it reads $\psi=\left(m_{Y}-r\right) / s_{Y}^{2}$, where $m_{Y}$ and $s_{Y}$ are the historical mean return and volatility of the benchmark, respectively, and $r$ is the historical mean yield on a suitable proxy of a risk-free asset. The unknown portfolio weights $\omega_{1}, \ldots, \omega_{k}$ are determined in three possible ways that are summarized for convenience in Table 1. Portfolios constructed by linear tracking or expected utility maximization are sought by using a proper optimization algorithm and are presented here with the ban on short sales. For these optimization methods, also some other constraints are conceivable and frequently practiced.

Table 1: Methods of portfolio construction considered

\begin{tabular}{ccc}
\hline Linear tracking & Expected utility maximization & Market capitalization \\
\hline $\min _{\substack{\omega_{1}, \ldots, \omega_{K} \geq 0 \\
\omega_{1}+\ldots+\omega_{K}=1}} \frac{1}{T} \sum_{t=1}^{t=T}\left|Y_{t}-\sum_{k=1}^{k=K} \omega_{k} x_{k, t}\right|$ & $\max _{\substack{\omega_{1}, \ldots, \omega_{K} \geq 0 \\
\omega_{1}+\ldots+\omega_{K}=1}} \sum_{k=1}^{k=K} \omega_{k} m_{k}-\frac{\psi}{2} \sum_{k=1}^{k=K} \sum_{l=1}^{l=K} \omega_{k} \omega_{l} \quad \omega_{k}=\Pi_{k} / \sum_{l=1}^{l=K} \Pi_{l}, \quad k \in\{1, \ldots, K\}$ \\
\hline
\end{tabular}

Source: the authors.

Suppose that a budget $B$ is available for the investment and the investor faces two forms of transaction costs, both being of a variable nature. Some costs are charged to the number of assets traded and some to the number of holdings purchased (or if also short positions were allowed, which is not the case at present). The lump charges of variable costs are denoted as $\chi_{A}$ per share traded and $\chi_{H}$ per holding of a share traded. Suppose that there are $K^{\#}$ non-zero weights in the (optimal) solution $\omega_{1}^{\#}, \ldots, \omega_{K}^{\#}$ of the procedures outlined in Table 1 , and assume further that the prices of assets at the instance of portfolio constructions are $P_{1}, \ldots, P_{K}$. The variable costs then amount to $k^{\#} \cdot \chi_{A}+\chi_{H} \cdot \sum\left|B^{\S} \cdot \omega_{i}^{\#} / P_{i}\right|$, where $B^{\S} \cdot \omega_{i}^{\#} / P_{i}$ denotes the holdings of an $i$-th asset derived from the net effective budget $B^{\S}$ that can be allocated to the investment after all the transactions costs applicable are met. This suggests solving for $B^{\S}$ the equation $B^{\S}=B-k^{\#} \cdot \chi_{A}-\chi_{H} \cdot \sum\left|B^{\S} \cdot \omega_{i}^{\#} / P_{i}\right|$. The considerations can be extended also for fixed costs and other transactions costs, but it transpires that these two forms are sufficient to control for transaction costs as was demonstrated in full in one of our previous studies (see Bod'a and Kanderová, 2016). 


\section{Experimental Set-up}

The experiment set the S\&P 500 as benchmark for a small investor who desires to form a portfolio of at most 50 constituent shares of the index. Choosing the S\&P 500 and its constituents is on account of its credit as this index is believed to represent well the patterns and sentiments of the American market. As many as 5 different datasets of historical weekly logarithmic returns of the S\&P 500 and its constituents between 2009 and 2016 were employed to pick up changing patterns of the American market, each dataset covering a period of four years. Two years were used for portfolio selection (in-sample period) and two years represented the investment horizon (out-of-sample period). These datasets are labeled and declared in tables as "20092012", "20102013" etc. until "20132016" and each data set is structured in the same way. For instance, dataset "20132016" covers on a weekly basis the insample period of 2013 and 2014 and the out-of-sample period of 2015 and 2016. It is assumed that in the middle of each dataset (when the in-sample period breaks into the out-of-sample period) the portfolio is created and then the buy-and-hold strategy is applied until the end of the out-of-sample period. At this end, the out-of-sample performance of the selected portfolio is previewed and assessed. Each in-sample period counted about 104 weekly returns and each out-of-sample period stretched over about 104 weeks.

At the moment of portfolio selection (in the midst of a dataset) the constituents of the S\&P 500 were screened using for their size (using market capitalization), their future prospects (using the $\mathrm{P} / \mathrm{B}$ and $\mathrm{P} / \mathrm{E}$ ratios) and past performance (using one-year historical yield inclusive of dividends). Equities represented in the S\&P 500 were ranked according to each screening criterion considered from one pole to another (from smallest to largest), but in the case of multiples and historical yield those equities that had an illegitimate (i.e. negative) value were skipped and the bottom or top equities were considered for pre-selection. For each pole, 10, 20, 30, 40 and 50 end equities were selected as candidates for portfolio selection. Of course, the omission of equities was done separately per each screening criterion, and therefore candidate sets of equities differed. As a result of this procedure, as many as 8 equity styles emerged: big/small market capitalization ("BCap", "SCap"), high/low P/B ratio ("HPB", "LPB"), high/low P/E ratio ("HPB", "HPE") and high/low yield ("HYld", "LYld"). Of course, an equity style based on investing into low yield shares does not exist and is considered here for completeness and for exhaustive comparison.

As was advertised in Section 2, the portfolio for each nominal size and each equity style in each dataset was finally selected by means of three different methods of portfolio selection: linear tracking ("LinTr"), expected exponential utility optimization ("MaxUt"), and market capitalization ("MarCap"). Of course, in linear tracking, the portfolio was selected so that its (weekly) returns reproduced as best as possible the S\&P 500 (weekly) returns over the insample period. The inputs to expected exponential utility optimization (i.e. the mean vector and the covariance matrix) were estimated using classical unbiased estimators and the riskaversion coefficients were determined for each dataset separately using the in-sample behaviour of the index and the method described in Section 2 above Table 1. The mean returns and volatilities of the S\&P 500 as well as the mean 1-year yields on US government securities on a weekly basis (p.w.) are displayed in Table 2. The risk-aversion coefficients on a weekly basis (p.w.) as well as those annualized by dint of the traditional square-root-of-time rule (p.a.) are shown in the last two columns of Table 2 . The annualization was advisable since financial community tend to think on an annual basis and also financial reporting is mostly with respect to this frequency. The level of risk aversion implied by the S\&P 500 and the investment into US securities (as a proxy of a risk-free asset) varied between 0.21 and 0.44 for datasets "20092012", "20102013" and "20112014", but exploded for the other two 
datasets. The reasons are also readable from Table 2, the mean two-year return of the S\&P 500 almost doubled whereas its two-year volatility halved for the periods $2012-2013$, 2013 - 2014. Furthermore, Table 2 appends weekly slope coefficients on regressions of the S\&P 500 values against time estimated for the reported two-year periods, which testify that in each two-year period the American market on average trended upwards with a weaker or greater intensity. Some evidence in this respect is provided in Figure 1 that slices the period under scrutiny into annual periods and shows fitted regression lines and reports one-year slope coefficients on these time regressions. Although in 2011 and 2015 the S\&P 500 on average followed a declining trajectory, taking a two-year horizon into account it increased.

Table 2: Risk aversion coefficients and slopes calculated for consecutive two-year periods between 2009 and 2016

\begin{tabular}{|c|c|c|c|c|c|c|}
\hline \multirow[b]{2}{*}{ Two-year period } & \multicolumn{2}{|c|}{ S\&P 500 Index } & \multirow{2}{*}{$\begin{array}{c}\text { 1-year US } \\
\text { treasury rate } \\
(\text { p. w.) }\end{array}$} & \multirow{2}{*}{$\begin{array}{l}\text { Slope trending } \\
\text { coefficient } \\
\text { (p. w.) }\end{array}$} & \multicolumn{2}{|c|}{ Implied risk-aversion coefficient } \\
\hline & $\begin{array}{l}\text { Mean return } \\
\text { (p. w.) }\end{array}$ & $\begin{array}{c}\text { Volatility } \\
\text { (p. w.) }\end{array}$ & & & $\begin{array}{c}\text { Weekly } \\
\text { (p.w.) }\end{array}$ & $\begin{array}{l}\text { Annualized } \\
\text { (p. a.) }\end{array}$ \\
\hline $2009-2010$ & 0.0029 & 0.0300 & $7.552 \mathrm{e}-05$ & 0.5500 & 3.1282 & 0.4424 \\
\hline $2010-2011$ & 0.0012 & 0.0271 & $4.800 \mathrm{e}-05$ & 0.2524 & 1.5062 & 0.2130 \\
\hline $2011-2012$ & 0.0015 & 0.0243 & $3.406 \mathrm{e}-05$ & 0.2249 & 2.4122 & 0.3411 \\
\hline $2012-2013$ & 0.0036 & 0.0151 & $2.938 \mathrm{e}-05$ & 0.7010 & 15.5111 & 2.1936 \\
\hline $2013-2014$ & 0.0033 & 0.0143 & $2.417 \mathrm{e}-05$ & 0.7861 & 15.8661 & 2.2438 \\
\hline $2014-2015$ & 0.0029 & 0.0300 & $4.274 \mathrm{e}-05$ & 0.3279 & 3.3403 & 0.4724 \\
\hline $2015-2016$ & 0.0012 & 0.0271 & $8.963 \mathrm{e}-05$ & 0.1604 & 2.1895 & 0.3096 \\
\hline
\end{tabular}

Source: the authors.

Figure 1: Values of the S\&P 500 Index between 2009 and 2016

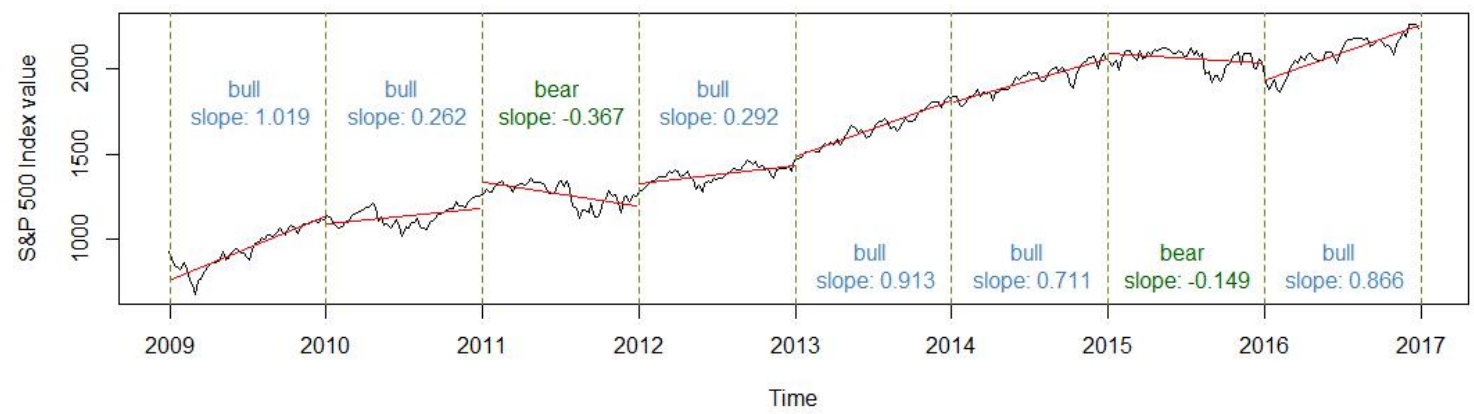

Source: the authors.

The usefulness of the eight equity styles in asset pre-selection was evaluated in the presence of transaction costs with the nominal budget available for investment $B=$ US\$ 10,000 , the amount of variable transaction costs $\chi_{A}=$ US $\$ 5$ per one unit of asset acquired, and the lump amount $\chi_{H}=$ US\$ 0.1 per unit of asset holding acquired. This configuration was designed in reference to an earlier study of ours (cf. Bod'a and Kanderová, 2016) in which the effect of transaction costs upon performance was studied. The values for $B$, $\chi_{A}$ and $\chi_{H}$ were chosen as a moderate and realistic variant.

The results are presented in the next section. In computations and preparing graphical presentations, the software R version 3.0.2 (R Core Team, 2013) was employed with several of its libraries, lpsolve (Berkelaar et al., 2015), quadprog (Turlach and Weingessel, 2013) and timeseries (Wuertz and Chalabi, 2013). 


\section{Results}

The success of one-stop shopping based on the four diametrical pairs of equity styles can only be evaluated in respect of its out-of-sample performance. Each portfolio arose by combining an equity style ("BCap", "SCap", HPB", "LPB", "HPB", "HPE", "HYld", "LYld"), a selection approach ("LinTr", MaxUt", "MarCap") and portfolio nominal size (10, 20, 30, 40, 50 shares), and for each dataset (from "20092012" to "20132016") was selected with the employment of a history of two years of weekly data. After a fictional investment of US\$ 10,000 has been made less the associated transaction costs, the portfolio was held without change non-rebalanced for another horizon of two years. At the end of this investment horizon, its performance was assessed against the performance of the underlying S\&P 500 Index via several criteria: (a) mean active return, (b) percentage of weeks of the investment period in which the portfolio fared better than the index did, and (c) total cumulative return. Many other measures are imaginable and some of them also were utilized in our previous studies, but after some experience in the field we find these most informative. Criteria (a) and (b) measure average performance over the investment period. The mean active return of a portfolio is the average of portfolio returns less benchmark returns, and it thus measures how on average the portfolio tended to outperform (or underperform) the benchmark in relative terms. Any fictional investment into a selected portfolio can be naturally compared to, and evaluated against, a parallel investment into the underlying benchmark. It is then natural to monitor how the selected portfolio values evolved and contrasted them with the benchmark values. This is expressed by the percentage of weeks in which an invested portfolio had higher values than the benchmark S\&P 500 Index did. It is a desideratum of investing to achieve returns as good as those of the benchmark (i.e. abnormal returns). Criterion (c) captures the ultimate outcome of the investment and measures how much the portfolio earned or lost on the initial nominal amount of investment over the investment horizon. Criterion (a) is expressed here on a weekly basis (p.w.), criterion (b) as a percentage and criterion (c) on a two-year basis.

The results are organized in Tables 3 and 4 and in Figure 2. For all constructed portfolios, Table 3 structures total two-year cumulative (discrete) returns and compares them to the total two-year cumulative return of the S\&P 500 Index made at 0.1334 . Portfolios that reported a loss are coloured red, portfolios that earned a profit below the index are coloured blue. Table 4 presents percentages of weeks in which portfolios with their values outperformed the comparable investment into the index. In order to enhance readability of information, those portfolios that constantly faltered under the index are displayed as "never" and only portfolios with percentages of $50 \%$ or higher are shown. Figure 2 compares mean active returns and percentages of better weeks for polar equity styles. Each scatter graph relates $\mathrm{S} / \mathrm{L}$ equity styles (on the horizontal axis) to corresponding $\mathrm{B} / \mathrm{H}$ counterparts (on the vertical axis). Through these scatter graphs identity lines are tended to show where polar equity styles give the same level of performance. In consequence, for those portfolios that are positioned in the right lower triangles, $\mathrm{S} / \mathrm{L}$ equity styles prevail over $\mathrm{B} / \mathrm{H}$ equity styles, whereas for portfolios in the left upper triangles $\mathrm{B} / \mathrm{H}$ equity styles are superior.

The results were evaluated on the scale of four summary descriptors and are for clarity further summarized in Table 5. The evaluation respected annual trends on the market as they are identified in Figure 1 and indicated by slope coefficients, and proceeded chiefly alongside these lines:

(1.) Portfolios with different poles (i.e. S/L vs. B/H) were compared in terms of mean active return for each investment period and screening criterion so as to find out what orientation prevailed in attaining higher returns: whether $\mathrm{S} / \mathrm{L}$ or $\mathrm{B} / \mathrm{H}$ equity styles were likely to 
warrant comparatively higher returns. The same pattern also applies (logically) for total cumulative returns.

(2.) Analogically, portfolios with different poles (i.e. S/L vs. B/H) were compared as well in terms of the percentage of weeks in which the index was surpassed and the prevalence of $\mathrm{S} / \mathrm{L}$ or $\mathrm{B} / \mathrm{H}$ equity styles for better performance was established.

(3.) Comparatively best portfolios were identified on the basis of mean active return (and correspondingly on the basis of total cumulative return) and its polarity, nominal size and selection method were compiled.

(4.) Finally, the best three equity styles and share pre-selections were noted down under the criterion of mean active return (as well as total cumulative return).

The results are at first glance very disparate and forbid easy generalization; yet, it is possible to read certain shared features that are associated with market cycle and alternating upward and downward phases of market price changes. Focusing upon two-year investment periods, three patterns in the entire period 2009 - 2016 can be discerned and pinpointed for the market as reflected in the S\&P 500 as follows from Figure 1 and Table 5.

1. Dataset "20092012": The out-of-sample period is bear-bull, in which a bear year is followed by a bull year with sluggish growth, with an almost constant trend and with low variability.

2. Datasets "20102013" and "20112014": The out-of-sample period is fully bull-bull with steady growth.

3. Datasets "20122015" and "20132016": The out-of-sample period is bear-bull or bull-bear with marked price changes reflected in higher volatility.

In the out-of-sample period with lower volatility and an almost constant trend (dataset "20092012") it is not clear which pole of equity styles prevails ( $\mathrm{S} / \mathrm{L}$ or $\mathrm{B} / \mathrm{H})$ with respect to mean active return, though percentage of weeks in which the index was outperformed suggests an inclination toward portfolios of $\mathrm{B} / \mathrm{H}$ equity styles. Portfolios that achieve the best mean active return are selected using equity style "LPB".

The bull-bull steadily growing out-of-sample periods (datasets "20102013" and "20112014") are plainly dominated by portfolios of S/L equity styles in respect of mean active return and in terms of percentage of outperforming weeks. It is also evident that smaller portfolios (with pre-selected 10, 20 and 30 shares) dominate. In this bull-bull stage of market cycle portfolios with a negative mean return are relatively scarce in comparison with those periods in which bear and bull years alternated. It is paradoxical that the most profitable equity style under mean active return is "LYld" with a pre-selection of 10 and 20 shares and with the maximum exponential utility selection method. This bizarre equity style based on weak past performance is obviously linked with cycles in equity prices and periods of decline (with negative returns) tend to be relieved by periods of rise (with positive returns). Should "LYld" be dismissed from considerations as an equity style, than the best portfolios in this out-of-sample period are those selected using equity style "LPE10".

In the out-of-sample periods with changing bear and bull patterns (datasets "20122015" and "20132016"), portfolios selected using B/H equity styles achieved generally higher mean active returns in comparison with those selected by means of $\mathrm{S} / \mathrm{L}$ equity styles. As regards percentage of outperforming weeks, in the case of dataset "20122015"it is difficult to find some uniform preferences for polarity of equity styles, but for dataset "20132016" B/H equity styles resulted in better performing portfolios than $\mathrm{S} / \mathrm{L}$ equity styles. This entire period is worst when percentage of outperforming weeks is considered. Nevertheless, in the times of higher volatility, portfolios selected on the basis of $\mathrm{B} / \mathrm{H}$ styles were found dominating without a doubt. This period when bear and bull years change abounds with negative or low positive mean returns. 
20th International Scientific Conference AMSE

Applications of Mathematics and Statistics in Economics 2017

Szklarska Poręba, Poland 30 August 2017 - 3 September 2017

Table 3: Cumulative returns of selected portfolios over two-year investment periods

\begin{tabular}{|c|c|c|c|c|c|c|c|c|c|c|c|c|c|}
\hline \multirow{2}{*}{ Dataset } & \multirow{2}{*}{$\begin{array}{c}\text { Selection } \\
\text { method }\end{array}$} & \multirow{2}{*}{$\begin{array}{l}\text { Equity } \\
\text { style }\end{array}$} & \multicolumn{5}{|c|}{ Portfolio nominal size (\# assets) } & \multirow{2}{*}{$\begin{array}{l}\text { Equity } \\
\text { style }\end{array}$} & \multicolumn{5}{|c|}{ Portfolio nominal size (\# assets) } \\
\hline & & & 10 & 20 & 30 & 40 & 50 & & 10 & 20 & 30 & 40 & 50 \\
\hline \multirow[t]{12}{*}{20092012} & LinTr & BCap & 0.230 & 0.163 & 0.153 & 0.209 & 0.142 & SCap & -0.189 & -0.107 & -0.040 & 0.090 & 0.159 \\
\hline & MarCap & & 0.211 & 0.394 & 0.315 & 0.286 & 0.260 & & -0.191 & 0.006 & 0.192 & 0.165 & 0.150 \\
\hline & MaxUt & & 0.648 & 0.648 & 0.615 & 0.299 & 0.127 & & 0.058 & 0.076 & 1.205 & 1.176 & 1.232 \\
\hline & $\operatorname{LinTr}$ & HPB & 0.141 & 0.040 & 0.063 & 0.050 & 0.047 & LPB & 0.091 & 0.041 & 0.118 & 0.148 & 0.066 \\
\hline & MarCap & & 0.295 & 0.231 & 0.220 & 0.198 & 0.169 & & -0.076 & 2.137 & 1.555 & 1.081 & 0.935 \\
\hline & MaxUt & & 0.325 & 0.346 & 0.360 & 0.312 & 0.225 & & 0.127 & 0.151 & 0.025 & 0.074 & 0.075 \\
\hline & $\operatorname{LinTr}$ & HPE & 0.184 & -0.048 & -0.070 & -0.006 & 0.025 & LPE & 0.350 & 0.265 & 0.224 & 0.115 & 0.060 \\
\hline & MarCap & & 0.136 & 0.121 & 0.116 & 0.117 & 0.108 & & 0.050 & 0.130 & 0.064 & 0.027 & -0.021 \\
\hline & MaxUt & & 0.218 & 0.274 & 0.274 & 0.227 & 0.411 & & 1.346 & 1.298 & 0.690 & 0.498 & 0.498 \\
\hline & LinTr & HYld & 0.242 & 0.073 & 0.002 & -0.008 & -0.063 & LYld & 0.074 & 0.202 & 0.194 & 0.046 & -0.002 \\
\hline & MarCap & & 0.024 & -0.076 & -0.095 & 0.119 & 0.072 & & 0.007 & 0.032 & 0.017 & 0.022 & 0.042 \\
\hline & MaxUt & & 0.389 & 0.234 & 0.170 & 0.170 & 0.170 & & 0.141 & 0.141 & 0.086 & 0.086 & 0.002 \\
\hline \multirow[t]{12}{*}{20102013} & LinTr & ВСар & 0.255 & 0.312 & 0.338 & 0.457 & 0.429 & SCap & 0.578 & 0.621 & 0.520 & 0.677 & 0.676 \\
\hline & MarCap & & 0.276 & 0.268 & 0.265 & 0.318 & 0.340 & & 1.356 & 0.90 & 0.847 & 0.852 & 0.798 \\
\hline & MaxUt & & 0.384 & 0.346 & 0.494 & 0.494 & 0.494 & & 0.170 & 0.267 & 0.822 & 1.081 & 1.081 \\
\hline & LinTr & HPB & 0.311 & 0.260 & 0.294 & 0.278 & 0.259 & LPB & 1.258 & 0.717 & 0.619 & 0.554 & 0.451 \\
\hline & MarCap & & 0.276 & 0.329 & 0.336 & 0.308 & 0.318 & & 1.239 & 1.091 & 0.956 & 0.902 & 0.829 \\
\hline & MaxUt & & 0.490 & 0.576 & 0.576 & 0.576 & 0.576 & & 1.120 & 0.897 & 0.809 & 0.809 & 1.093 \\
\hline & LinTr & HPE & 0.323 & 0.264 & 0.437 & 0.384 & 0.403 & LPE & 1.086 & 0.698 & 0.736 & 0.687 & 0.596 \\
\hline & MarCap & & 0.554 & 0.291 & 0.374 & 0.336 & 0.321 & & 0.721 & & & 0.450 & 0.442 \\
\hline & MaxUt & & -0.143 & 0.576 & 0.576 & 0.576 & 0.576 & & 1.353 & 1.180 & 1.180 & 1.180 & 0.858 \\
\hline & LinTr & HYld & 0.227 & 0.485 & 0.256 & 0.379 & 0.377 & LYld & 1.340 & 0.837 & 0.744 & 0.746 & 0.712 \\
\hline & MarCap & & 0.606 & 0.566 & 0.347 & 0.384 & 0.369 & & 1.408 & 1.138 & 0.831 & 0.768 & 0.749 \\
\hline & MaxUt & & 0.576 & 0.576 & 0.576 & 0.576 & 0.576 & & 3.059 & 2.408 & 1.832 & 1.637 & 1.328 \\
\hline \multirow[t]{12}{*}{20112014} & LinTr & BCap & 0.068 & 0.120 & 0.304 & 0.295 & 0.217 & SCap & 0.691 & 0.652 & 0.487 & 0.427 & 0.446 \\
\hline & MarCap & & -0.011 & 0.084 & 0.143 & 0.168 & 0.163 & & 0.655 & 74 & 0.434 & 0.365 & 0.444 \\
\hline & MaxUt & & -0.465 & -0.206 & 0.516 & 0.625 & 0.171 & & 0.775 & 0.220 & 0.254 & 0.344 & 0.344 \\
\hline & LinTr & HPB & 0.591 & 0.372 & 0.309 & 0.354 & 0.318 & LPB & 0.783 & & 0.399 & 0.419 & 0.475 \\
\hline & MarCap & & 0.356 & 0.188 & 0.153 & 0.178 & 0.174 & & 0.4 & & 0.449 & 0.448 & 0.423 \\
\hline & MaxUt & & 0.635 & 0.599 & -0.559 & -0.559 & -0.469 & & 0.784 & 0.264 & 0.319 & 0.319 & 0.368 \\
\hline & LinTr & HPE & 0.622 & 0.443 & 0.387 & 0.349 & 0.342 & LPE & 0.857 & 0.591 & 0.591 & 0.612 & 0.558 \\
\hline & MarCap & & 0.420 & 0.330 & 0.328 & 0.327 & 0.319 & & 1.050 & & 0.233 & 0.274 & 0.308 \\
\hline & MaxUt & & 0.812 & 0.812 & 0.812 & 0.614 & 0.614 & & 0.594 & 0.651 & 0.651 & 0.651 & 0.592 \\
\hline & LinTr & HYld & 0.371 & 0.495 & 0.420 & 0.448 & 0.350 & LYld & 1.181 & & 0.555 & 0.437 & 0.359 \\
\hline & MarCap & & 0.372 & 0.301 & 0.331 & 0.364 & 0.349 & & 1.004 & 0.407 & 0.256 & 0.325 & 0.295 \\
\hline & MaxUt & & 0.335 & 0.365 & 0.463 & 0.456 & 0.456 & & 2.005 & 1.075 & 1.061 & 0.579 & 0.581 \\
\hline \multirow[t]{12}{*}{20122015} & $\operatorname{LinTr}$ & BCap & -0.028 & -0.013 & 0.006 & -0.009 & 0.024 & SCap & 0.05 & 0.036 & 0.036 & 0.025 & 0.120 \\
\hline & MarCap & & -0.115 & -0.060 & -0.019 & -0.034 & -0.036 & & -0.178 & -0.132 & -0.115 & -0.109 & -0.072 \\
\hline & MaxUt & & 0.039 & 0.174 & 0.247 & -0.175 & -0.131 & & 0.058 & 0.088 & 0.049 & 0.046 & 0.249 \\
\hline & LinTr & HPB & 0.340 & 0.138 & 0.187 & 0.166 & 0.176 & LPB & -0.019 & -0.075 & -0.062 & -0.042 & -0.012 \\
\hline & MarCap & & 0.376 & 0.099 & 0.133 & 0.121 & 0.111 & & 0.00 & 0.005 & -0.018 & -0.018 & -0.045 \\
\hline & MaxUt & & 0.345 & -0.054 & -0.070 & -0.070 & 0.016 & & 0.148 & 0.061 & 0.060 & 0.136 & 0.035 \\
\hline & $\operatorname{LinTr}$ & HPE & 0.228 & 0.126 & 0.137 & 0.127 & 0.075 & LPE & -0.020 & -0.118 & -0.052 & -0.067 & -0.075 \\
\hline & MarCap & & 0.338 & 0.267 & 0.232 & 0.140 & 0.135 & & 0.073 & -0.023 & -0.006 & -0.016 & -0.057 \\
\hline & MaxUt & & 0.322 & 0.360 & 0.418 & 0.295 & 0.273 & & 0.074 & -0.004 & 0.073 & 0.177 & 0.175 \\
\hline & $\operatorname{LinTr}$ & HYld & 0.065 & 0.146 & 0.155 & 0.037 & 0.097 & LYld & -0.245 & 0.011 & 0.037 & 0.012 & -0.008 \\
\hline & MarCap & & 0.050 & 0.016 & 0.045 & 0.033 & 0.005 & & -0.153 & -0.038 & -0.060 & -0.073 & -0.055 \\
\hline & MaxUt & & 0.111 & 0.324 & 0.309 & 0.236 & 0.177 & & -0.20 & -0.052 & 0.046 & 0.108 & 0.130 \\
\hline \multirow[t]{12}{*}{20132016} & LinTr & ВСар & 0.096 & 0.076 & 0.146 & 0.088 & 0.106 & SCap & -0.138 & 0.061 & 0.073 & 0.038 & 0.097 \\
\hline & MarCap & & 0.108 & 0.114 & 0.126 & 0.093 & 0.090 & & -0.232 & -0.128 & -0.111 & -0.099 & -0.029 \\
\hline & MaxUt & & 0.134 & 0.113 & 0.157 & 0.174 & 0.260 & & -0.055 & 0.222 & 0.113 & 0.022 & 0.190 \\
\hline & $\operatorname{LinTr}$ & HPB & 0.050 & 0.093 & 0.080 & 0.058 & 0.059 & LPB & 0.129 & 0.140 & 0.156 & 0.141 & 0.172 \\
\hline & MarCap & & 0.011 & 0.073 & 0.159 & 0.122 & 0.085 & & 0.133 & 0.096 & 0.129 & 0.128 & 0.117 \\
\hline & MaxUt & & -0.014 & 0.076 & 0.001 & -0.113 & -0.006 & & 0.182 & 0.150 & 0.285 & 0.312 & 0.205 \\
\hline & LinTr & HPE & -0.075 & -0.033 & -0.059 & -0.065 & -0.056 & LPE & -0.185 & -0.001 & 0.030 & 0.018 & -0.031 \\
\hline & MarCap & & -0.136 & -0.180 & -0.019 & -0.027 & -0.033 & & -0.071 & -0.049 & -0.044 & 0.035 & -0.010 \\
\hline & MaxUt & & & -0.081 & 0.108 & 0.058 & 0.058 & & -0.119 & -0.033 & -0.033 & -0.059 & -0.050 \\
\hline & LinTr & HYld & -0.069 & & & -0.014 & 0.020 & LYld & & & -0.020 & -0.109 & -0.008 \\
\hline & MarCap & & -0.036 & -0.039 & -0.083 & 0.0 & 0.005 & & -0.397 & -0.272 & 0.335 & 0.170 & 0.114 \\
\hline & MaxUt & & 0.046 & 0.022 & -0.061 & -0.029 & -0.012 & & -0.268 & -0.130 & 0.063 & -0.218 & -0.107 \\
\hline
\end{tabular}

Note: Negative total cumulative returns are printed in red whereas positive total cumulative returns that are lower than the total cumulative return $13.34 \%$ earned on the index are printed in blue. Legend: The meaning of abbreviations is as follows: "LinTr" - linear tracking, "MarCap" - market capitalization, "MaxUt" - expected utility maximization, "BCap"/"SCap" big/small capitalization, "HPB"/"LPB" - high/low price-to-book ratio, "HPE"/"LPE" - high/low price-to-earnings ratio "HYld"/"LYld" - high/low yield.

Source: the authors. 
Table 4: Relative lengths of two-year investment periods in which selected portfolios outperformed the index in terms of their value

\begin{tabular}{|c|c|c|c|c|c|c|c|c|c|c|c|c|c|}
\hline \multirow{2}{*}{ Dataset } & \multirow{2}{*}{$\begin{array}{c}\text { Selection } \\
\text { method }\end{array}$} & \multirow{2}{*}{$\begin{array}{c}\text { Equity } \\
\text { style }\end{array}$} & \multicolumn{5}{|c|}{ Portfolio nominal size (\# assets) } & \multirow{2}{*}{$\begin{array}{l}\text { Equity } \\
\text { style }\end{array}$} & \multicolumn{5}{|c|}{ Portfolio nominal size (\# assets) } \\
\hline & & & 10 & 20 & 30 & 40 & 50 & & 10 & 20 & 30 & 40 & 50 \\
\hline \multirow[t]{11}{*}{20092012} & LinTr & BCap & $97 \%$ & $75 \%$ & $79 \%$ & $69 \%$ & $66 \%$ & SCap & & never & never & & \\
\hline & MarCap & & $82 \%$ & $83 \%$ & $82 \%$ & $82 \%$ & $82 \%$ & & & & & & \\
\hline & MaxUt & & $91 \%$ & $91 \%$ & $91 \%$ & $68 \%$ & & & $75 \%$ & $73 \%$ & & & \\
\hline & LinTr & $\mathrm{HPB}$ & $93 \%$ & & $54 \%$ & & & LPB & & & & & \\
\hline & MarCap & & $87 \%$ & $84 \%$ & $86 \%$ & $86 \%$ & $83 \%$ & & & $87 \%$ & $87 \%$ & $86 \%$ & $84 \%$ \\
\hline & MaxUt & & $68 \%$ & $99 \%$ & $99 \%$ & $99 \%$ & $94 \%$ & & & & & & \\
\hline & LinTr & HPE & & never & never & never & never & LPE & $91 \%$ & $51 \%$ & & & \\
\hline & $\begin{array}{l}\text { MarCap } \\
\text { MaxUt }\end{array}$ & & $51 \%$ & $64 \%$ & $64 \%$ & $\begin{array}{c}\text { never } \\
61 \%\end{array}$ & $99 \%$ & & & & never & never & never \\
\hline & LinTr & HYld & $88 \%$ & $61 \%$ & & never & never & LYld & & & & never & never \\
\hline & MarCap & & & & never & & & & & & & & \\
\hline & MaxUt & & $99 \%$ & $83 \%$ & $65 \%$ & $65 \%$ & $65 \%$ & & & & $66 \%$ & $66 \%$ & \\
\hline \multirow[t]{12}{*}{20102013} & LinTr & BCap & & & & & never & SCap & $91 \%$ & $98 \%$ & $86 \%$ & $78 \%$ & $97 \%$ \\
\hline & MarCap & & & & & & & & $94 \%$ & $73 \%$ & $71 \%$ & $74 \%$ & $73 \%$ \\
\hline & MaxUt & & $51 \%$ & $51 \%$ & $67 \%$ & $67 \%$ & $67 \%$ & & & & $92 \%$ & $85 \%$ & $85 \%$ \\
\hline & LinTr & HPB & never & never & never & & never & LPB & $99 \%$ & $79 \%$ & & & never \\
\hline & MarCap & & & & & & & & $99 \%$ & $98 \%$ & $94 \%$ & $92 \%$ & $86 \%$ \\
\hline & MaxUt & & $80 \%$ & & & & & & $99 \%$ & $90 \%$ & $51 \%$ & $51 \%$ & $86 \%$ \\
\hline & LinTr & HPE & & & $58 \%$ & $56 \%$ & & LPE & $92 \%$ & $79 \%$ & $58 \%$ & $62 \%$ & \\
\hline & MarCap & & $58 \%$ & & $51 \%$ & $51 \%$ & & & $92 \%$ & $88 \%$ & $80 \%$ & & \\
\hline & MaxUt & & & & & & & & $98 \%$ & $99 \%$ & $99 \%$ & $99 \%$ & $99 \%$ \\
\hline & LinTr & HYld & & & never & never & never & LYld & $96 \%$ & $98 \%$ & $78 \%$ & $72 \%$ & $65 \%$ \\
\hline & MarCap & & $55 \%$ & & never & & & & $99 \%$ & $98 \%$ & $84 \%$ & $83 \%$ & $78 \%$ \\
\hline & MaxUt & & & & & & & & $77 \%$ & $85 \%$ & $76 \%$ & $87 \%$ & $83 \%$ \\
\hline \multirow[t]{12}{*}{20112014} & LinTr & BCap & never & never & never & never & never & SCap & $97 \%$ & $97 \%$ & $98 \%$ & & $62 \%$ \\
\hline & MarCap & & never & never & never & never & never & & $90 \%$ & $86 \%$ & $81 \%$ & $63 \%$ & $80 \%$ \\
\hline & MaxUt & & never & & $68 \%$ & $70 \%$ & & & $98 \%$ & & & & \\
\hline & LinTr & HPB & $80 \%$ & $59 \%$ & & & & LPB & $97 \%$ & $98 \%$ & $78 \%$ & $92 \%$ & $97 \%$ \\
\hline & MarCap & & & & never & never & never & & $76 \%$ & $84 \%$ & $81 \%$ & $80 \%$ & $66 \%$ \\
\hline & MaxUt & & $77 \%$ & $92 \%$ & & & & & $98 \%$ & & & & \\
\hline & LinTr & HPE & $97 \%$ & $86 \%$ & & never & never & LPE & $97 \%$ & $97 \%$ & $95 \%$ & $91 \%$ & $90 \%$ \\
\hline & MarCap & & $96 \%$ & & & & never & & $98 \%$ & $90 \%$ & never & never & never \\
\hline & MaxUt & & $86 \%$ & $86 \%$ & $86 \%$ & $61 \%$ & $61 \%$ & & $76 \%$ & $93 \%$ & $93 \%$ & $93 \%$ & $91 \%$ \\
\hline & LinTr & HYld & & $52 \%$ & & & & LYld & $99 \%$ & $71 \%$ & $98 \%$ & $96 \%$ & \\
\hline & MarCap & & & never & & & & & $99 \%$ & $67 \%$ & & & never \\
\hline & MaxUt & & & & & & & & $96 \%$ & $94 \%$ & $94 \%$ & $99 \%$ & $98 \%$ \\
\hline \multirow[t]{12}{*}{20122015} & LinTr & BCap & & never & never & never & never & SCap & $63 \%$ & never & never & never & \\
\hline & MarCap & & & never & never & never & never & & & & & & \\
\hline & MaxUt & & & & $51 \%$ & & & & & & $60 \%$ & & $95 \%$ \\
\hline & $\operatorname{LinTr}$ & HPB & $56 \%$ & & & & $56 \%$ & LPB & never & never & never & never & $58 \%$ \\
\hline & MarCap & & & never & & & never & & & never & never & never & never \\
\hline & MaxUt & & & never & never & never & & & & & & $82 \%$ & $67 \%$ \\
\hline & LinTr & HPE & & $64 \%$ & $64 \%$ & $72 \%$ & & LPE & $56 \%$ & never & & & \\
\hline & MarCap & & & & & & & & & & never & never & never \\
\hline & MaxUt & & $66 \%$ & $66 \%$ & $82 \%$ & $54 \%$ & $56 \%$ & & $82 \%$ & & $50^{\circ}$ & $99 \%$ & $99 \%$ \\
\hline & LinTr & HYld & & $72 \%$ & $58 \%$ & & & LYld & & $70 \%$ & & & \\
\hline & MarCap & & $59 \%$ & $71 \%$ & $55 \%$ & & never & & & $66 \%$ & & & \\
\hline & MaxUt & & & $90 \%$ & $93 \%$ & $85 \%$ & $66 \%$ & & & & & & $68 \%$ \\
\hline \multirow[t]{12}{*}{20132016} & LinTr & BCap & & & $62 \%$ & & & SCap & & & & & $76 \%$ \\
\hline & MarCap & & & $57 \%$ & $68 \%$ & $51 \%$ & & & & & never & never & \\
\hline & MaxUt & & $68 \%$ & $56 \%$ & $89 \%$ & $99 \%$ & $99 \%$ & & & $74 \%$ & $73 \%$ & & $93 \%$ \\
\hline & LinTr & HPB & $54 \%$ & $64 \%$ & & & & LPB & & & & & \\
\hline & MarCap & & & $64 \%$ & $97 \%$ & $95 \%$ & $89 \%$ & & & & & & \\
\hline & MaxUt & & $69 \%$ & $79 \%$ & $79 \%$ & & $69 \%$ & & & & $77 \%$ & $78 \%$ & $66 \%$ \\
\hline & LinTr & HPE & & never & & never & never & LPE & & & never & never & never \\
\hline & MarCap & & & & & & & & never & & never & never & never \\
\hline & MaxUt & & $65 \%$ & & $92 \%$ & $66 \%$ & $66 \%$ & & & never & never & never & never \\
\hline & LinTr & HYld & & & & & & LYld & never & never & & never & never \\
\hline & MarCap & & & & & never & & & never & never & $92 \%$ & $55 \%$ & \\
\hline & MaxUt & & & & & & & & never & never & & never & never \\
\hline
\end{tabular}

Note: In order to assure readability, only percentages higher than $50 \%$ are displayed, and those portfolios whose values developed constanly beneath the fictional investment into the index are listed as "never". Legend: The meaning of abbreviations is as follows: "LinTr" - linear tracking, "MarCap" - market capitalization, "MaxUt" - expected utility maximization, "BCap"/"SCap" - big/small capitalization, "HPB"/"LPB" - high/low price-to-book ratio, "HPE"/"LPE" high/low price-to-earnings ratio, "HYld"/"LYld" - high/low yield.

Source: the authors. 
Figure 2: Out-of-sample performance of selected portfolios in two-year investment horizon with a comparison of "S/L" and "B/H" equity styles
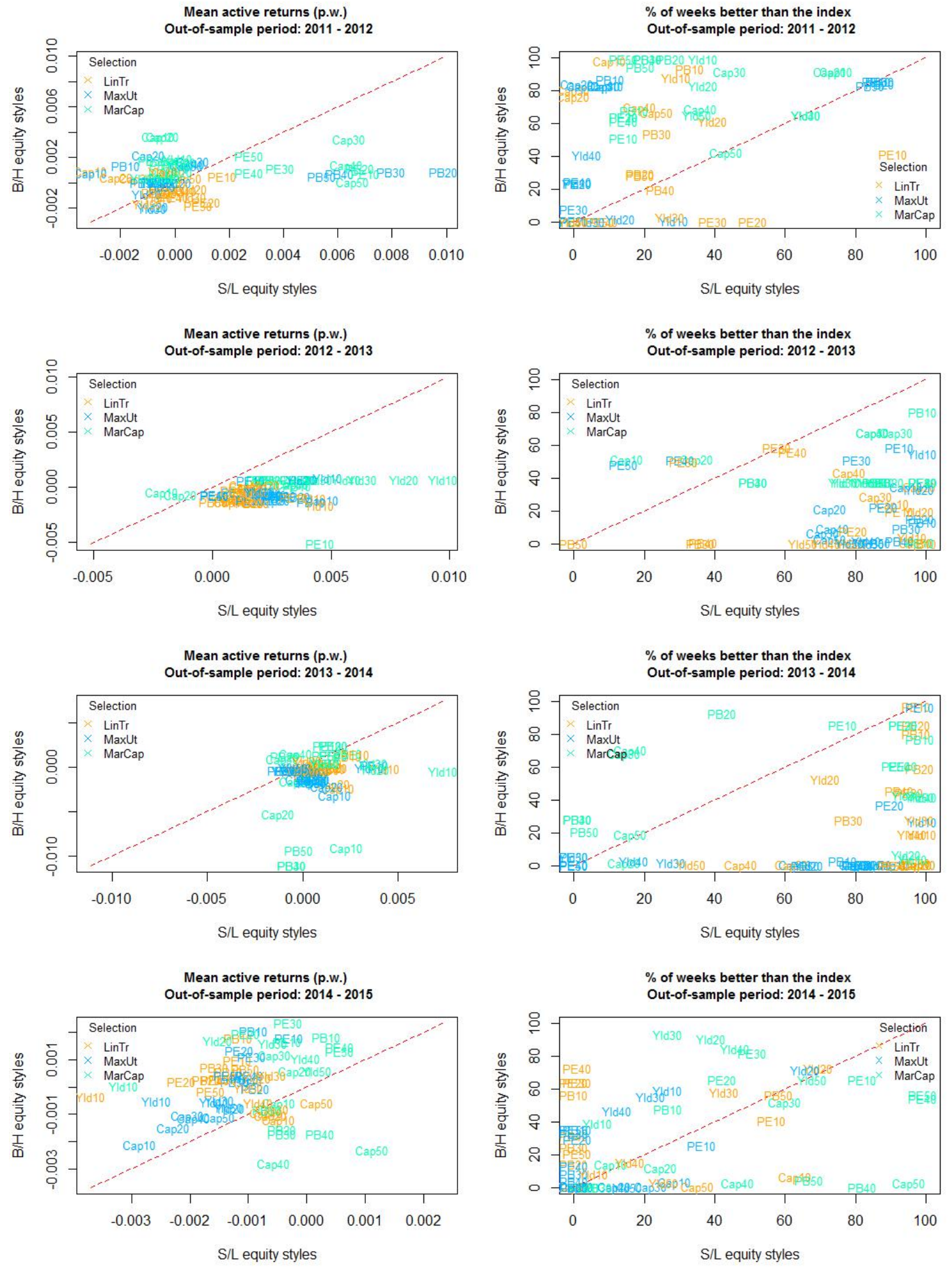

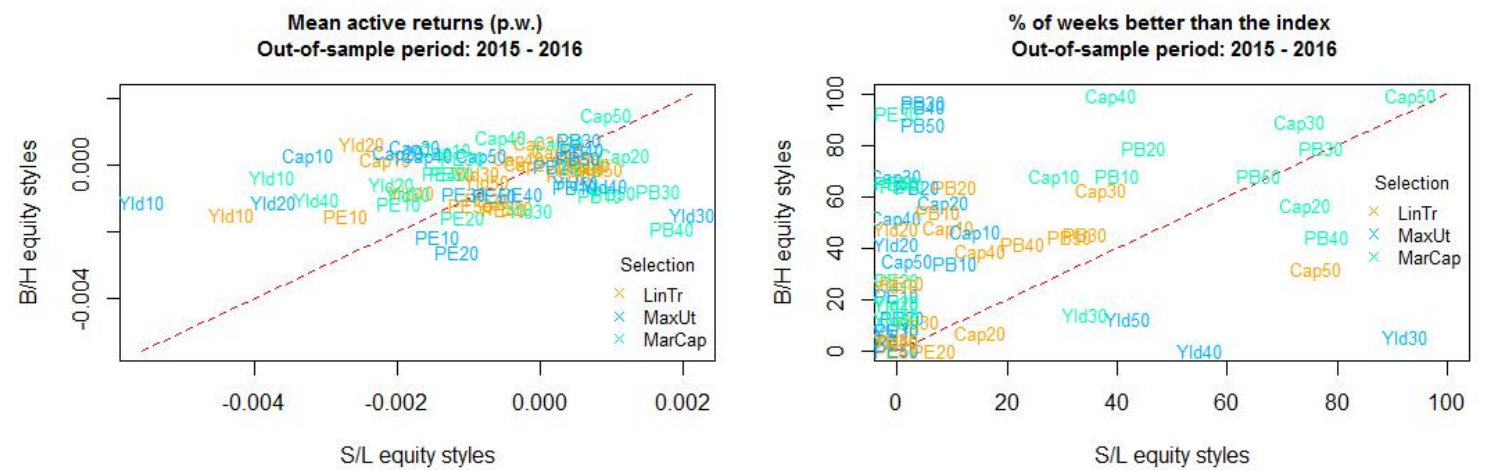

Source: the authors.

Table 5: Summary of key findings

\begin{tabular}{|c|c|c|c|c|c|c|c|c|}
\hline \multirow{4}{*}{ Period } & \multirow{4}{*}{$\begin{array}{l}\text { Trending } \\
\text { phase } \\
\text { (slope) }\end{array}$} & & \multicolumn{4}{|c|}{ Comparative superiority for } & \multirow{2}{*}{\multicolumn{2}{|c|}{$\begin{array}{l}\text { Best strategies in terms of mean active return } \\
\text { (arranged by desirability in decreasing order) }\end{array}$}} \\
\hline & & & \multirow{2}{*}{\multicolumn{2}{|c|}{$\begin{array}{l}\text { Mean active } \\
\text { return }\end{array}$}} & \multirow{2}{*}{\multicolumn{2}{|c|}{$\begin{array}{l}\text { \% weeks better } \\
\text { than the index }\end{array}$}} & & \\
\hline & & & & & & & \multirow{2}{*}{ Pole \& \# assets \& (method) } & \multirow{2}{*}{$\begin{array}{c}\text { Top } 3 \\
\text { strategies }\end{array}$} \\
\hline & & & Pole & Method & Pole & Method & & \\
\hline \multirow{2}{*}{$\begin{array}{l}\text { In-sample } \\
(20092010)\end{array}$} & & & B & & $\mathrm{B}$ & & & \multirow{4}{*}{$\begin{array}{l}\text { LPB20 LinTr } \\
\text { LPB30 LinTr } \\
\text { LPE10 MaxUt }\end{array}$} \\
\hline & & PB & Both & & $\mathrm{H}$ & & & \\
\hline \multirow{2}{*}{$\begin{array}{l}\text { Investment } \\
(20112012)\end{array}$} & & $\mathrm{PE}$ & & & The & & \multirow{2}{*}{$\begin{array}{c}\text { L 10, 20, } 30 \text { (MaxU)t } \\
\text { H } 10 \text { (LinTr), H } 20 \text { (MaxUt) L } 20 \text { (LinTr) }\end{array}$} & \\
\hline & & Yld & Both & & $\mathrm{H}$ & & & \\
\hline \multirow{2}{*}{$\begin{array}{l}\text { In-sample } \\
(20102011)\end{array}$} & & Cap & $\mathrm{S}$ & & $\sigma_{0}$ & & \multirow{2}{*}{$\begin{array}{l}\text { S } 10 \text { (LinTr), S 40, } 50 \text { (MarCap) } \\
\text { L } 10 \text { (LinTr, MarCap, MaxUt) }\end{array}$} & \multirow{4}{*}{$\begin{array}{l}\text { LYld10 MaxUt } \\
\text { LYld } 20 \text { MaxUt } \\
\text { LYld } 30 \text { MaxUt }\end{array}$} \\
\hline & & $\mathrm{P}$ & $\mathrm{L}$ & & I & & & \\
\hline \multirow{2}{*}{$\begin{array}{l}\text { Investment } \\
(20122013)\end{array}$} & & & $\mathrm{L}$ & & & & \multirow{2}{*}{$\begin{array}{l}\text { L 10, 20, 30, } 40 \text { (MaxUt) } \\
\text { L 10, 20,30, } 40 \text { (MaxUt) }\end{array}$} & \\
\hline & & & $\mathrm{L}$ & & $\mathrm{L}$ & & & \\
\hline \multirow{2}{*}{$\begin{array}{l}\text { In-sample } \\
(20112013)\end{array}$} & & $\mathrm{Ca}$ & $\mathrm{S}$ & & & & \multirow{2}{*}{$\begin{array}{c}\text { S } 10 \text { (LinTr, MarCap, MaxUt) } \\
\text { L } 10 \text { (LinTr, MaxUt), L } 20 \text { (LinTr) }\end{array}$} & \multirow{4}{*}{$\begin{array}{l}\text { LYld10 MaxUt } \\
\text { LYld20 MaxUt } \\
\text { LYld30 MaxUT }\end{array}$} \\
\hline & & $\mathrm{PF}$ & $\mathrm{L}$ & & & & & \\
\hline \multirow{2}{*}{$\begin{array}{l}\text { Investment } \\
(20132014)\end{array}$} & & & Both & & & & \multirow{2}{*}{$\begin{array}{c}\text { L } 10 \text { (MarCap, LinTr, MaxUt) } \\
\text { L } 10 \text { (MaxUt, LinTr), L } 20 \text { (MaxUt) }\end{array}$} & \\
\hline & & & $\mathrm{L}$ & & I & & & \\
\hline \multirow{2}{*}{$\begin{array}{l}\text { In-sample } \\
(20122013)\end{array}$} & & & Both & & $\mathrm{S}$ & & & \multirow{4}{*}{$\begin{array}{l}\text { HPE30 MaxUt } \\
\text { HPB10 MarCap } \\
\text { HPE20 MaxUt }\end{array}$} \\
\hline & & $\mathrm{PF}$ & $\mathrm{H}$ & & & & & \\
\hline \multirow{2}{*}{$\begin{array}{l}\text { Investment } \\
(20142015)\end{array}$} & & $\mathrm{PE}$ & $\mathrm{H}$ & & $\mathrm{H}$ & & \multirow{2}{*}{$\begin{array}{c}\text { H 30, } 20 \text { (MaxUt), H } 10 \text { (MarCap) } \\
\text { H 20, 30, } 40 \text { (MaxUt) }\end{array}$} & \\
\hline & & & $\mathrm{H}$ & & $\mathrm{H}$ & & & \\
\hline & & Cap & B & & B & & B 30, S 20, B 40 (MaxUt) & \multirow{4}{*}{$\begin{array}{l}\text { LYld30 MarCap } \\
\text { LPB40 MaxUt } \\
\text { LPB30 MaxUt }\end{array}$} \\
\hline & & PB & $\mathrm{S}$ & & $\mathrm{H}$ & & & \\
\hline ment & $\operatorname{ar}(-0.15)$ & $\mathrm{PE}$ & Both & MaxUt & $\mathrm{H}$ & MaxUt & H 30, 40, 50 (MaxUt) & \\
\hline (20152016) & Bull $(0.86)$ & Yld & $\mathrm{H}$ & $\operatorname{LinTr}$ & $\mathrm{S}$ & $\mathrm{MarCaP}$ & L 30, 40 (MarCap), B 20 (LinTr) & \\
\hline
\end{tabular}

Legend: The meaning of abbreviations is as follows: "S" - small, "L" - low , "B" - big, "H" - high, "Cap" - capitalization. "PB" - price-to-book ratio, "PE" - price-to-earnings ratio, " Yld" - yield", "LinTr" - linear tracking, "MarCap" - marke capitalization, "MaxUt" - expected utility maximization.

Source: the authors.

In order to account for the factors that dominate in explaining the performance of the selected portfolios a search was initiated using traditional methods of regression model selection. Four competing approaches counted LASSO (for details see e.g. Tibshirani, 1996), selection aiming at maximization of the Bayesian information criterion (BIC), selection founded on minimization of Mallow's $C_{p}$ (see e.g. Mallows, 1973), and selection based on maximization of adjusted R-squared (Adj $\mathrm{R}^{2}$ ). The best models explaining mean active returns, percentage of better weeks and total cumulative return for all the portfolios constructed are reported in Table 6 . In fitting, the results of individual datasets were merged into a larger dataset and the three factors of performance were explained by nominal portfolio size (the number of pre-selected shares), actual portfolio size (the actual number of shares), the polarity of equity styles ("S/L" against "B/H"), the screening criterion ("Cap", "PB", "PE", "Yld"), the portfolio selection method ("LinTr", "MaxUt", "MarCap") and the dataset ("20092012" to "20132016"). 
Table 6: Explanatory factors of portfolio performance identified in a regression context

\begin{tabular}{|c|c|c|c|c|c|c|c|c|c|c|c|c|}
\hline \multirow{2}{*}{ Variable } & \multicolumn{4}{|c|}{ Mean active return } & \multicolumn{4}{|c|}{$\begin{array}{c}\% \text { of weeks } \\
\text { better than the index }\end{array}$} & \multicolumn{4}{|c|}{ Total cumulative return } \\
\hline & LASSO & BIC & $\mathbf{C}_{\mathbf{p}}$ & Adj $\mathbf{R}^{2}$ & LASSO & BIC & $C_{p}$ & $\operatorname{Adj} R^{2}$ & LASSO & BIC & $\mathbf{C}_{\mathrm{p}}$ & Adj $R^{2}$ \\
\hline $\begin{array}{c}\text { Intercept } \\
\# \text { assets }\end{array}$ & -0.006 & 0.002 & 0.006 & 0.027 & 47.12 & 53.52 & 43.93 & 59.63 & $\begin{array}{c}0.157 \\
-0.002\end{array}$ & 0.110 & $\begin{array}{c}0.171 \\
-0.002\end{array}$ & 0.118 \\
\hline Actual \# assets & & & & & -0.474 & -0.695 & -0.501 & -0.698 & & & & \\
\hline $\begin{array}{c}\text { Pole (SL) } \\
\text { Criterion (PB) }\end{array}$ & 0.055 & 0.079 & 0.079 & 0.079 & 2.36 & & 6.70 & & 0.108 & 0.150 & 0.150 & 0.150 \\
\hline Criterion (PE) & 0.016 & & & & & & & & 0.037 & & & \\
\hline Criterion (Yld) & & & & & & & & & 0.009 & & & \\
\hline $\begin{array}{l}\text { Style (HPB) } \\
\text { Style (HPE) }\end{array}$ & -0.013 & & & & & & & & -0.004 & & & \\
\hline Style (HYld) & & & & & -7.46 & & & & & & & \\
\hline $\begin{array}{l}\text { Style (LPB) } \\
\text { Style (LPE) }\end{array}$ & 0.043 & & & & & & & & 0.077 & & & \\
\hline $\begin{array}{l}\text { Style (LYld) } \\
\text { Style (Scap) }\end{array}$ & & & & & 0.62 & & & & $\begin{array}{c}0.064 \\
-0.001\end{array}$ & & & \\
\hline Selection (I & & 0.008 & & & & & & & 0.004 & 0.017 & & \\
\hline Selection (MaxUt) & 0.053 & 0.067 & 0.063 & 0.063 & 6.20 & & 8.16 & & 0.126 & 0.140 & 0.131 & 0.131 \\
\hline Dataset (20102013) & 0.051 & 0.042 & 0.042 & & 8.70 & 10.91 & 11.04 & & 0.428 & 0.434 & 0.434 & 0.434 \\
\hline Dataset (20112014) & -0.036 & -0.064 & -0.064 & -0.085 & 4.97 & 7.24 & 7.32 & & 0.187 & 0.193 & 0.193 & 0.193 \\
\hline Dataset (20122015) & -0.084 & -0.113 & -0.113 & -0.134 & -9.17 & -11.30 & -11.50 & -17.34 & -0.172 & -0.178 & -0.178 & -0.178 \\
\hline Dataset (20132016) & -0.095 & -0.123 & -0.123 & -0.144 & -8.16 & -10.41 & -10.51 & -16.46 & -0.209 & -0.216 & -0.216 & -0.216 \\
\hline
\end{tabular}

Note: Since "Pole", "Criterion", "Style", "Selection" and "Dataset" are all categorical variables, during their transformation tc dummy variables one redundant value in each case was dropped in order to ensure feasibility. When one of them takes $\mathrm{K}$ values, in the model selection only its $\mathrm{K}-1$ values recoded to $\{0,1\}$ were considered to escape the perfect collinearity trap Legend: The meaning of abbreviations is as follows: "SL" - small/low, "HPB"/"LPB" - high/low price-to-book ratio "HPE"/"LPE" - high/low price-to-earnings ratio, "HYld"/"LYld" - high/low yield (and this extends analogically to shorte versions "PB", PE", "Yld"), "SCap" - small capitalization, "MarCap" - market capitalization, "MaxUt" - expected utility maximization. "LASSO", "BIC", " $\mathrm{C}_{\mathrm{p}}$ " and "Adj $\mathrm{R}^{2 "}$ are traditional selection criteria explained in more detail in the text.

Source: the authors.

The views on the structure of performance offered by divers identification criteria and summarized in Table 6 are fairly congruent. It seems that the most contributive explanatory factors are: (effective or nominal) portfolio size, polarity, selection method and period reflecting market cycle. It is not surprising that portfolio size is considered to be detrimental to the ability of selected portfolios to outperform the benchmark index. Positive signs on S/L equity styles are in line with general thoughts and consistent with majority opinion that smallsize and low-multiple portfolios are preferable and warrant higher returns in the future. It also transpires that maximum exponential utility is a generally preferable selection method and on average increases mean active returns by 0.05 or $0.06 \mathrm{p} . \mathrm{w}$. and total cumulative returns by 0.13 or 0.14 per two years. Another factor that becomes apparent is that also the stage of market cycle matters, although with this explanatory factor there are some disparate results between the three criteria of performance. Nevertheless, the portfolios selected for datasets "20102013" and "20112014" when investment periods were bull-bull displayed comparatively higher performance, whereas the portfolios selected using the last two datasets "20122015" and "20132016" delivered comparatively poorer performance

\section{Conclusion}

Using the limited time span of five consecutive datasets and restricted to a fraction of the US equity market represented by the S\&P 500 Index, we found that in periods of bull markets showing stable growth investors should prefer small portfolios (created from a pre-selection of 30 assets at most) and should rely on maximum exponential utility as a selection criterion. It is somewhat unexpected to discover that "LYld" equity style based on low historical yield (or poor past performance) should be recommendable, but this obviously must be associated 
with the fact that in real investment conditions it is not tenable for most equities to display constant returns and times of prosperity (higher returns) are exchanged by adverse conditions (lower returns or losses). After a period of underperformance vital firms should recover and should be capable of picking up rising trends.

For periods of market rises and declines when bull and bear markets alternate it is impossible to draw firm advice about preference of an equity style or portfolio selection method. That being said, some tentative recommendation may be given in favour of the $\mathrm{P} / \mathrm{B}$ and $\mathrm{P} / \mathrm{E}$ ratio as screening criteria oriented on growth shares with high values of this multiple. This finding is nothing untoward in the light of the fact that many studies (such as Zhang et al., 2008) observe that performance of various equity styles is crucially linked with market states and business cycle. More specifically, Kwag and Lee (2006), Arshanapalli and Nelson (2007) as well as Bod'a and Kanderová (2017) prove that value equity styles lead to higher performance in bear markets than growth equity styles do. On the contrary, growth portfolios are better performers in bull markets as is also corroborated by the present findings.

The results also prove that performance of equity styles is much dependent on market regime. What is not considered here and presents an idea for future work is that portfolios selected by combining different investment styles could be more reliable as this combined selection strategy would lessen their dependence on economic and market cycles as is also shown in the studies of Boudt and Peeters (2013) and Arshanapalli and Nelson (2007). Another aspect worthy of consideration is the length of investment period, which was in the paper two years. Possibly, if a shorter (or a longer) investment period would be used in the analysis, the conclusions might be different. In point of fact, a number of studies demonstrated (see e.g. Chaves and Arnott, 2012) that over the long term value equity style tend outperform growth style and this outperformance applies to shares with both large and small capitalization.

\section{Acknowledgements}

The paper arose in fulfilment of the VEGA project \# 1/0554/16 Alternatives to replicating portfolio selection in the conditions of frequent rebalancing.

\section{References}

[1] Alexander, C. 2008. Market risk analysis. Volume I: Quantitative methods in finance. Chichester: Wiley, 2008. ISBN 978-0-470-99800-7.

[2] Arshanapalli, B.G., Nelson, W.B. 2007. Small cap and value investing offer both high returns and a hedge. In Journal of Wealth Management, vol. 9, no. 4, pp. 44-50.

[3] Berkelaar, $M$ et al. 2015. lpSolve: interface to 'Lp_solve' v. 5.5 to solve linear/integer programs. $\mathrm{R}$ package, version 5.6.13. Available at: http://cran.r-project.org/web/ packages/lpSolve/index.html.

[4] Bod'a, M., Kanderová, M. 2017. Investment style preference and its effect upon performance of tracking portfolios. Forthcoming in Acta Unversitatis Agriculturae et Silviculturae Brunensis.

[5] Bod'a, M., Kanderová, M. 2016. Comparison of approaches for asset pre-selection in portfolio tracking. In Bod'a, M., Mendelová, V. (eds.) Applications of Mathematics and Statistics 2016. Conference proceedings. Banská Bystrica: Občianske združenie Financ, 2016. ISBN 978-80-89438-04-4. Pp. 44-57.

[6] Boudt, K., Peeters, B. 2013. Smart harvesting of equity style premia. Finvex fourth white paper. Finvex Group, 2013. [cit. 31-01-2017] http://finvex.com/wp/wp-content/uploads/ Finvex-wp4-01-2013-Web.pdf. 
[7] Chaves, B.D., Arnott, R. 2012. Rebalancing and the value effect. In Journal of Portfolio Management, vol. 38, iss. 4, pp. 59-74.

[8] Grinold, R.C., Kahn, R.N. 1995. Active portfolio management. Burr Ridge (IL, USA): Irwin/Mc-Graw Hill, 1995. ISBN 1-55738-824-5.

[9] Kwag, S.W., Lee, S.W. 2006. Value investing and the business cycle. In Journal of Financial Planning, vol. 19, iss. 1, pp. 1-10.

[10]Lofthouse, S. 1994. Equity investment management - how to select stocks and markets. New York: Wiley, 1994. ISBN 978-0471941699.

[11] Mallows, C.L. 1973. Some Comments on $C_{P}$. Technometrics, vol. 15, iss. 4, pp. 661-675.

[12] Markowitz, H. 1987. Mean-variance analysis in portfolio choice and capital markets. Oxford: Basil Blackwell, 1989. ISBN 0-631-15381-0.

[13]Penman, S.H. 2010. Financial statement analysis and security valuation. 4th ed. Boston: McGraw-Hill, 2010. ISBN 978-007-126780-9.

[14]R Core Team 2013: R: a language and environment for statistical computing. Vienna: R Foundation for Statistical Computing, http://www.r-project.org/.

[15] Turlach, B.A., Weingessel, A. 2013. quadprog: functions to solve quadratic programming problems. R package, version 1.5-5, http://cran.r-project.org/package =quadprog.

[16] Tibshirani, R. 1996. Regression shrinkage and selection via the Lasso. In Journal of the Royal Statistical Society, series B, vol. 58, iss. 1, pp. 267-288.

[17]Wuertz, D., Chalabi, Y. 2013. timeSeries: Rmetrics - financial time series objects. R package, version 3010.97, http://cran.r-project.org/web/packages/timeSeries/index.

[18]Zhang, Q. J. et al. 2008. The link between macro-economic factors and style returns. In Journal of Asset Management, vol. 10, iss. 5, pp. 338-355. 
20th International Scientific Conference AMSE

Applications of Mathematics and Statistics in Economics 2017

Szklarska Poręba, Poland

30 August 2017 - 3 September 2017 